\title{
Relationship between Positive Glucose Screening, Obesity and Pregnancy Outcome in the Absence of Gestational Diabetes: A Retrospective Cohort Study
}

\author{
Kassam Mahomed ${ }^{1,2 *}$, Sharleen Young ${ }^{2}$, Ibinebo Ibiebele ${ }^{3}$, Jane V. Hoare ${ }^{1}$ \\ ${ }^{1}$ Ipswich Hospital, Ipswich, UK \\ ${ }^{2}$ University of Queensland, Brisbane, Australia \\ ${ }^{3}$ Mater Medical Research Institute, Brisbane, Australia \\ Email: ${ }^{*}$ Kassam Mahomed@health.qld.gov.au
}

Received 28 April 2014; revised 25 May 2014; accepted 2 June 2014

Copyright (C) 2014 by authors and Scientific Research Publishing Inc.

This work is licensed under the Creative Commons Attribution International License (CC BY).

http://creativecommons.org/licenses/by/4.0/

c) (7) Open Access

\section{Abstract}

Background: Currently pregnant women with abnormal glucose screening test (GCT), performed at 26 - 28 weeks gestation with a subsequent normal glucose tolerance test (GTT) receive routine care. Could these women be at risk of adverse pregnancy? Objective: Compare rate of caesarean section (CS), induction of labour (IOL), macrosomia, admission to special care nursery and neonatal hypoglycaemia. Designs: Retrospective cohort study. Setting: Ipswich Hospital, Ipswich, Queensland. Participants: Pregnant women having had the test at the hospital laboratory. Methods: Charts review of outcome measures including induction of labour, caesarean section, macrosomia, RDS and short-term neonatal morbidity. Results: We reviewed 882 charts $(441$ cases and 441 controls). There was a higher IOL rate among cases $21.1 \%$ versus $16.6 \%$ (OR and $95 \%$ CI 1.45 ; 1.03 - 2.06) and a higher CS rate, 30.4 versus 23.6 (OR and 95\% CI 1.41; 1.05 - 1.91). Compared to women with BMI 18.5 - 24.9, women with BMI of 30 and above had a significantly higher IOL rate (47.1\% versus $22.6 \%)$, higher CS rate $(47.2 \%$ versus $25.7 \%)$ and higher rate of macrosomic baby (79.2\% versus $4.2 \%)$. There were more women amongst the cases who were older, smoked, had a BMI 30 and above and had previous history of GDM. After adjusting for maternal age, BMI and smoking status, there was still an increased odds of CS, IOL and macrosomia, but this did not reach statistical significance. Conclusion: Abnormal glucose screening test in the absence of gestational diabetes is associated with adverse pregnancy outcome. This is largely contributed by maternal obesity.

\footnotetext{
Corresponding author.
} 


\section{Keywords}

\section{Positive Glucose Screening Test, Gestational Diabetes, Obesity and Pregnancy Outcome}

\section{Introduction}

In Queensland, Australia, it is a standard practice for all pregnant women to have a 50 g glucose challenge test (GCT) at 26 - 28 weeks gestation. Those who have an abnormal test (1 hour value $7.8 \mathrm{mmols} / \mathrm{l}$ or above) are requested to have a fasting $75 \mathrm{~g}$ oral glucose tolerance test (GTT). Women with a fasting value of 7.0 or above or a 2-hour value of 11.1 or above are defined as diabetic and those with fasting $5.5-6.9$ or a 2-hour value of 7.8 or above and less than 11.1 are defined as gestational diabetics [1].

Currently women who have had an abnormal GCT and a normal GTT receive routine antenatal care. A recent study has shown that there was a statistically significant increase in risk of preeclampsia, caesarean section (CS) and neonatal hypoglycaemia with increasing levels of blood sugar with the GCT [2]. As these findings were based only on the GCT, the group probably included some women who may have developed GDM.

A 10-year audit [3] and a review of a subgroup of the population from the ACTS trial [4] have suggested that women with a positive GCT and a negative GTT may be at increased risk of preeclampsia, CS, hypoglycaemia and hyperbilirubinaemia compared to women with normal GCT. These results do not however appear to have been controlled for any confounding variables.

There has been only one small (150 women in each group) controlled trial [5] that stratified such women by age and BMI and that noted no significant difference between untreated women with positive GCT and negative GTT compared to controls with negative GCT, with regard to CS rate, macrosomia, admission to neonatal intensive care unit or in neonatal hypoglycaemia. There were significantly more newborns with a higher ponderal index among the cases.

Primary objective of our study was to obtain a larger sample size to compare the CS rates in these two groups. Secondary objective was to compare outcomes such as induction of labour (IOL), macrosomia, admission to SCN and neonatal hypoglycaemia and to explore the association between these outcomes and the test status.

\section{Methods}

This was a retrospective cohort study conducted at Ipswich General Hospital, Ipswich, Queensland from January 2004 to December 2010. The study was approved by the Darling Downs and West Morton Health Service District Human Research Ethics Committee. Eligible women were those who had both their GCT (at 26 - 28 weeks gestational age confirmed at the first booking in visit) and GTT both performed at the Ipswich Hospital Pathology Department. Cases were women who had a positive 50 g GCT and a normal 75 g GTT. For each case the control was the next woman tested at the same laboratory and around the same gestation but with a normal GCT result. Both groups would normally have received the standard care as for non GDM women. Data on pregnancy and birth outcomes were extracted from medical charts.

Differences between the two groups in relation to maternal characteristics were tested using Student's t test for normally distributed continuous data. Differences between proportions for categorical data was tested using Chi-square test, otherwise Fisher's exact test was used when there was a count of 5 or less.

The relationship between test status and each maternal characteristic and pregnancy outcome variable was initially explored using univariate logistic regression. Maternal characteristics found to have a statistically significant relationship with GCT status were incorporated into the multivariate logistic regression models examining the association between GCT status and each of the following variables [IOL, CS, macrosomia (birthweight > $4000 \mathrm{~g}$ ), admission to special care nursery and neonatal hypoglycaemia].

Statistical significance was set at a two sided p value of $<0.05$. Stata/SE version 9.0 for Windows (StataCorp LP, College Station, Texas, USA) was used for statistical analysis.

The sample size calculation is based on the hypothesis that there will be a 50\% increase in the proportion of women undergoing caesarean section (from an estimated $20 \%$ in the control group to $30 \%$ in the positive GCT group). A sample size of 882 (441 cases and 441 controls) will provide over 90\% power to detect a difference of $50 \%$ in the proportion of caesarean sections with an alpha level of 0.5 . 


\section{Results}

During the study period we reviewed charts of 882 participants (441 cases and 441 controls). Demographic characteristics of the women in the two groups are shown in Table 1. There were significantly more women amongst the cases who were older (mean age 28.6 years versus 26.0 years, $\mathrm{p}<0.001$ ), had a BMI of 30 and above $(42.8 \%$ versus $31.8 \%, \mathrm{p}=0.007)$, had previous history of Gestational diabetes $(2.7 \%$ versus $0.6 \%$, $\mathrm{p}=$ $0.064)$ and were smokers $(33.7 \%$ versus $26.8 \%, p=0.025)$. There were fewer women amongst the cases who

Table 1. Characteristics of women with positive GCT compared with women with a normal GCT.

\begin{tabular}{|c|c|c|c|}
\hline Characteristics & $\begin{array}{c}\text { Positive GCT (cases) } \\
\mathrm{n}=441(\%)\end{array}$ & $\begin{array}{c}\text { Normal GCT (controls) } \\
\mathrm{n}=441(\%)\end{array}$ & $\mathrm{p}$ value \\
\hline \multicolumn{4}{|l|}{ Maternal age (years) } \\
\hline Mean \pm sd & $28.6 \pm 6.1$ & $26.0 \pm 5.5$ & \multirow{2}{*}{$<0.000^{\mathrm{a}}$} \\
\hline Missing & 0 & 0 & \\
\hline \multicolumn{4}{|l|}{ Gravida } \\
\hline 1 & $107(24.4)$ & $117(26.5)$ & \multirow{2}{*}{0.093} \\
\hline Missing & 2 & 0 & \\
\hline \multicolumn{4}{|l|}{ Body mass index $\left(\mathrm{kg} / \mathrm{m}^{2}\right)$} \\
\hline$<18.5$ & $6(1.5)$ & $10(2.5)$ & \multirow{5}{*}{0.007} \\
\hline $18.5-24.9$ & $106(26.2)$ & $139(34.2)$ & \\
\hline $25-29.9$ & $119(29.5)$ & $128(31.5)$ & \\
\hline$\geq 30$ & $173(42.8)$ & $129(31.8)$ & \\
\hline Missing & 37 & 35 & \\
\hline Smoking & $148(33.7)$ & $118(26.8)$ & \multirow{2}{*}{0.025} \\
\hline Missing & 2 & 0 & \\
\hline Previous gestational diabetes mellitus & $9(2.7)$ & $2(0.6)$ & \multirow{2}{*}{$0.064^{\mathrm{b}}$} \\
\hline Missing & 108 & 119 & \\
\hline Previous hypertension & $40(9.1)$ & $35(7.9)$ & \multirow{2}{*}{0.532} \\
\hline Missing & 2 & 0 & \\
\hline \multicolumn{4}{|l|}{ Ethnicity } \\
\hline Caucasian & $344(78.0)$ & 355 (80.5) & \multirow{5}{*}{0.481} \\
\hline ATSI $^{*}$ & $18(4.1)$ & $22(5.0)$ & \\
\hline Samoan & $50(11.3)$ & $45(10.2)$ & \\
\hline Asian & $12(2.7)$ & $10(2.3)$ & \\
\hline Others & $17(3.9)$ & $9(2.0)$ & \\
\hline \multicolumn{4}{|l|}{ Marital status } \\
\hline Never married & $58(13.3)$ & 82 (18.9) & \multirow{4}{*}{0.075} \\
\hline Married/de facto & 371 (84.9) & $344(79.1)$ & \\
\hline Divorced/separated & $8(1.8)$ & $9(2.1)$ & \\
\hline Missing & 4 & 6 & \\
\hline
\end{tabular}

*Aboriginal and/or Torres Strait Islander; ${ }^{\mathrm{a}}$ Values are mean \pm standard deviation, and the comparisons are mean difference; ${ }^{\mathrm{b}}$ Fisher's exact. 
were never married $(13.3 \%$ versus $18.9 \%$, overall $\mathrm{p}=0.075)$. About four-fifths of the cases and controls were Caucasian and married or in a de-facto relationship.

Association between glucose status and pregnancy complications and outcomes are shown in Table 2. Compared to controls, there was a higher IOL rate among cases $21.1 \%$ versus 16.6\% (OR 1.45, 95\% CI 1.03 - 2.06, p $=0.020$ ) and a higher CS rate, 30.4\% versus $23.6 \%$ (OR 1.41, 95\% CI $1.05-1.91, \mathrm{p}=0.023$ ), mostly contributed by failure to progress. None of the others differences were statistically significant. The leading indications for induction of labour were the same for both groups; post dates $(40.4 \%)$ and spontaneous rupture of membranes (17.5\%).

Regardless of GCT status there was an increased odds of IOL (OR 2.24, 95\% CI 1.43 - 3.53), CS (OR 1.74, 95\% CI 1.18 - 2.55), and macrosomia (birth weight > 4000 g) (OR 16.3, 95\% CI 2.17 - 122.6) among obese women compared with women with normal range BMI. There was no significant association between obesity and either neonatal hypoglycaemia or admission to SCN (Table 3).

After adjusting for maternal age, BMI and smoking status, a positive GCT was associated with increased odds of IOL (aOR 1.43, 95\% CI 0.98 - 2.07), CS (aOR 1.20, 95\% CI 0.86 - 1.67) and macrosomia (aOR 2.07, 95\% CI 0.83 - 5.20) and a decreased odds of admission to SCN (aOR 0.97, 95\% CI 0.62 - 1.52). However none of these associations reached statistical significance (Table 4).

\section{Discussion}

This is the largest study to date showing that women who have an abnormal GCT but a normal GTT, and who are generally treated as low-risk women actually have an increased odds of IOL, CS and macrosomia. However after adjusting for the effect of maternal age, smoking and BMI, these were not statistically significant.

These findings of higher CS rate concur with those from South Australia [2] [4] but we did not show any increased rate of neonatal hypoglycaemia. The South Australian data used blood glucose levels of GCT and probably included women with GDM.

It is of note however that there were significantly more women who had a high BMI, who were older and who smoked amongst the cases. After controlling for these factors, there was still an increased odds of IOL, CS and

Table 2. Association between GCT status and pregnancy outcomes.

\begin{tabular}{lcccc}
\hline & (Cases) $\mathrm{n}=441(\%)$ & (Controls) $\mathrm{n}=441(\%)$ & OR [95\% CI] & $\mathrm{p}$ value \\
\hline Pregnancy complications & $38(8.6)$ & $41(9.3)$ & $0.92[0.58,1.46]$ & 0.724 \\
Induction of labour & $93(21.1)$ & $73(16.6)$ & $1.45[1.03,2.06]$ & 0.020 \\
Caesarean section & $134(30.4)$ & $104(23.6)$ & $1.41[1.05,1.91]$ & 0.023 \\
Epidural & $62(14.1)$ & $63(14.3)$ & $0.98[0.67,1.43]$ & 0.923 \\
3rd/4th degree tear & $6(1.4)$ & $6(1.4)$ & $1.10[0.35,3.47]$ & 0.053 \\
Birth weight (grams) Mean \pm sd & $3495 \pm 572$ & $3479 \pm 523$ & $1.00[1.00-1.00]$ & 0.680 \\
$\quad>4500$ (ref: $\leq 4500$ g) & $18(4.1)$ & $9(2.1)$ & $2.03[0.90,4.57]$ & 0.082 \\
$\quad$ Missing & 2 & 5 & $0.99[0.91-1.07]$ & 0.736 \\
Gestational age at birth (weeks) Mean \pm sd & $39.2 \pm 1.5$ & $39.2 \pm 1.8$ & $1.00[0.55,1.81]$ & 1.000 \\
$\quad$ <37 weeks (ref: $\geq 37$ wks) & $23(5.2)$ & $23(5.2)$ & $1.17[0.39,3.51]$ & 0.780 \\
$\quad 7(1.6)$ & $6(1.4)$ & $2.0[0.18,22.1]$ & 0.564
\end{tabular}


Table 3. Association between maternal BMI category and selected pregnancy outcomes.

\begin{tabular}{|c|c|c|c|c|}
\hline \multicolumn{5}{|c|}{ Induction of labour ${ }^{*}$} \\
\hline & Yes $(n=155)$ & No $(n=541)$ & OR (95\% CI) & $\mathrm{p}$ value \\
\hline \multicolumn{5}{|l|}{ BMI $\left(\mathrm{kg} / \mathrm{m}^{2}\right)$} \\
\hline$<18.5$ & $0(0.0)$ & $12(2.2)$ & - & - \\
\hline $18.5-24.9$ & 35 (22.6) & $185(34.2)$ & Referent & - \\
\hline $25-29.9$ & 47 (30.3) & $172(31.8)$ & $1.44(0.89-2.34)$ & 0.137 \\
\hline$\geq 30$ & $73(47.1)$ & $172(31.8)$ & $2.24(1.43-3.53)$ & 0.000 \\
\hline \multicolumn{5}{|c|}{ Caesarean section } \\
\hline & Yes $(n=214)$ & No $(n=596)$ & OR (95\% CI) & $\mathrm{p}$ value \\
\hline \multicolumn{5}{|l|}{ BMI $\left(\mathrm{kg} / \mathrm{m}^{2}\right)$} \\
\hline$<18.5$ & $5(2.3)$ & $11(1.9)$ & $1.57(0.52-4.71)$ & 0.421 \\
\hline $18.5-24.9$ & 55 (25.7) & 190 (31.9) & Referent & - \\
\hline $25-29.9$ & $53(24.8)$ & $194(32.6)$ & $0.94(0.62-1.45)$ & 0.791 \\
\hline$\geq 30$ & $101(47.2)$ & 201 (33.7) & $1.74(1.18$ - 2.55) & 0.005 \\
\hline \multicolumn{5}{|c|}{ Macrosomia (birth weight > 4500 g) } \\
\hline & Yes $(n=24)$ & No $(n=780)$ & OR (95\% CI) & $\mathrm{p}$ value \\
\hline \multicolumn{5}{|l|}{ BMI $\left(\mathrm{kg} / \mathrm{m}^{2}\right)$} \\
\hline$<18.5$ & $0(0.0)$ & $16(2.1)$ & - & - \\
\hline $18.5-24.9$ & $1(4.2)$ & 241 (30.9) & Referent & - \\
\hline $25-29.9$ & $4(16.7)$ & $242(31.0)$ & $3.98(0.44$ - 35.9) & 0.218 \\
\hline$\geq 30$ & $19(79.2)$ & $281(36.0)$ & $16.3(2.17-122.6)$ & 0.007 \\
\hline \multicolumn{5}{|c|}{ Admission to SCN } \\
\hline & Yes $(n=95)$ & No $(n=714)$ & OR (95\% CI) & $\mathrm{p}$ value \\
\hline \multicolumn{5}{|l|}{ BMI $\left(\mathrm{kg} / \mathrm{m}^{2}\right)$} \\
\hline$<18.5$ & $3(3.2)$ & $13(1.8)$ & $1.72(0.46-6.39)$ & 0.419 \\
\hline $18.5-24.9$ & $29(30.5)$ & $216(30.3)$ & Referent & - \\
\hline $25-29.9$ & $25(26.3)$ & $221(31.0)$ & $0.84(0.48-1.49)$ & 0.554 \\
\hline$\geq 30$ & $38(40.0)$ & $264(37.0)$ & 1.07 (0.64 - 1.80) & 0.791 \\
\hline \multicolumn{5}{|c|}{ Neonatal hypoglycaemia } \\
\hline & Yes $(n=17)$ & No $(n=793)$ & OR (95\% CI) & $\mathrm{p}$ value \\
\hline \multicolumn{5}{|l|}{ BMI $\left(\mathrm{kg} / \mathrm{m}^{2}\right)$} \\
\hline$<18.5$ & $1(5.9)$ & $15(1.9)$ & $2.00(0.23-16.8)$ & 0.534 \\
\hline $18.5-24.9$ & $8(47.1)$ & 237 (29.9) & Referent & - \\
\hline $25-29.9$ & $3(17.7)$ & $244(30.8)$ & $0.36(0.10-1.39)$ & 0.139 \\
\hline$\geq 30$ & $5(29.4)$ & $297(37.5)$ & $0.50(0.16-1.54)$ & 0.228 \\
\hline
\end{tabular}

"Analysis excludes women who had no labour. 
Table 4. Association between positive GCT status and selected pregnancy outcomes adjusted for maternal age, BMI and smoking status.

\begin{tabular}{|c|c|c|c|c|}
\hline Variable & Odds ratio $(\mathrm{aOR})^{*}$ & Standard error & p value & $95 \%$ CI \\
\hline Caesarean section & 1.20 & 0.20 & 0.298 & $0.86-1.67$ \\
\hline Induction of labour & 1.43 & 0.28 & 0.060 & $0.98-2.09$ \\
\hline Macrosomia (>4500 g) & 2.07 & 0.97 & 0.119 & $0.83-5.20$ \\
\hline Admission to special care nursery & 0.97 & 0.22 & 0.910 & $0.62-1.52$ \\
\hline Neonatal hypoglycaemia & 1.00 & 0.51 & 0.998 & $0.37-2.71$ \\
\hline
\end{tabular}

macrosomia, however the association was not statistically significant. The lack of statistical significance could be due to the sample size (study was not powered to undertake multivariate analysis). These results suggest that although women with positive screening in the absence of GDM have an increased odds of IOL, CS and macrosomia, it is the high BMI, advanced maternal age and smoking that contribute to the trend towards the increased risk of adverse outcomes amongst the cases and that should be of concern in any intervention strategy. GCT may be a marker to alert clinicians to look at other interventions in caring for such women. The association between obesity and adverse pregnancy outcomes is not new. A Danish population-based study [6] of women with raised BMI but normal glucose levels reported that the risk of hypertensive complications, caesarean section, induction of labour and macrosomia was significantly increased in both overweight women and obese women compared with women who were of normal weight. A UK-based study [7] also showed a clear dose dependent association between increasing BMI and macrosomia, the relative risk increasing by 1.7, 2.7 and 4.8 with overweight, obese and morbidly obese women respectively. Others have similarly reported a strong association between BMI and risk of macrosomic baby [8]-[11], and risk of caesarean section [7]-[13] even when women with GDM were excluded [8].

The association between BMI and induction of labour is also not new. Several studies have shown that women with increased BMI are more likely to require IOL [6] [10] [13]. It is not clear why this may be so. Some have noted an increased risk of post dates as the indication [10] but this did not seem to be the case in our cohort. It is possible that women with high BMI have other complications that increase the need for induction of labour, although we were not able to demonstrate this in our study either, but this could be a cascade of events starting with post dates, a difficult induction of labour and eventually other interventions including a caesarean section.

This study clearly demonstrates the need for careful assessment of women who have an abnormal GCT particularly if they happen to be obese. Several recent publications [14]-[16] recommend that all obese pregnant women should be offered advice regarding sensible weight reduction, including diet, exercise and referral to a dietician where appropriate. Despite excluding women with GDM, there is evidence that even lesser degrees of hyperglycaemia may have additional risks of adverse pregnancy outcome as shown by the HAPO study [17]. With the obesity epidemic seen in most well resourced countries ( $40 \%$ of nulliparae's pregnant women in a study from UK [9] were overweight), it is mandatory that more rigorous and well organised interventions become a health priority. Obesity confers an increased life-time risk of type 2 diabetes and potential interventions in pregnancy appearing promising [18]. Whilst these are still relatively short-term benefits ideally, rigorous interventions need to be targeted at a much earlier age, probably from preschool years.

This large cohort study has clearly shown that a pregnant woman with a high BMI and an abnormal GCT is not a low-risk pregnancy and should be referred for additional multidisciplinary care.

\section{References}

[1] Alberti, K.G. and Zimmet, P.Z. (1998) Definition, Diagnosis and Classification of Diabetes Mellitus and Its Complications. Part 1: Diagnosis and Classification of Diabetes Mellitus: Provisional Report of a WHO Consultation. Diabetic Medicine, 15, 539-553. http://dx.doi.org/10.1002/(SICI)1096-9136(199807)15:7<539::AID-DIA668>3.0.CO;2-S

[2] Dodd, J.M., Crowther, C.A., Antoniou, G., Baghurst, P. and Robinson, J.S. (2007) Screening for Gestational Diabetes: The Effect of Varying Blood Glucose Definitions in the Prediction of Adverse Maternal and Infant Health Outcomes. Australian \& New Zealand Journal of Obstetrics and Gynaecology, 47, 307-312. 
http://dx.doi.org/10.1111/j.1479-828X.2007.00743.x

[3] Crowther, C.A., McPhee, A.J., et al. (2012) The IDEAL Study: Investigation of Dietary Advice and Lifestyle for Women with Borderline Gestational Diabetes: A Randomised Controlled Trial. BMC Pregnancy and Childbirth, 12, 106. http://dx.doi.org/10.1186/1471-2393-12-106

[4] Rumbold, A.R., Crowther, C.A., Haslam, R.R., Dekker, G.A., Robinson, J.S. and for the ACTS Study Group (2006) Vitamins C and E and the Risks of Preeclampsia and Perinatal Complications. New England Journal of Medicine, 254, 1796-1806. http://dx.doi.org/10.1056/NEJMoa054186

[5] Bonomo, M., Corica, D., Mion, D., Gonçalves, D., Motta, G., Merati, R., Ragusa, A. and Morabito, A. (2005) Evaluating the Therapeutic Approach in Pregnancies Complicated by Borderline Glucose Intolerance: A Randomized Clinical Trial. Diabetic Medicine, 22, 1536-1541. http://dx.doi.org/10.1111/j.1464-5491.2005.01690.x

[6] Jensen, D.M., Damm, P., Sorensen, B., et al. (2003) Pregnancy Outcome and Prepregnancy Body Mass Index in 2459 Glucose Tolerant Danish Women. American Journal of Obstetrics \& Gynecology, 189, 239-244. http://dx.doi.org/10.1067/mob.2003.441

[7] Khashan, A.S. and Kenny, L.C. (2009) The Effects of Maternal Body Mass Index on Pregnancy Outcome. European Journal of Epidemiology, 24, 397-405. http://dx.doi.org/10.1007/s10654-009-9375-2

[8] Owens, L.A., O’Sullivan, E.P., Kirwan, B., Avalos, G., Gaffney, G., Dunne, F. and ATLANTIC DIP Collaborators (2010) ATLANTIC DIP: The Impact of Obesity on Pregnancy Outcome in Glucose-Tolerant Women. Diabetes Care, 33, 577-579. http://dx.doi.org/10.2337/dc09-0911

[9] Mantakas, A. and Farrell, T. (2010) The Influence of Increasing BMI in Nulliparous Women on Pregnancy Outcome. European Journal of Obstetrics \& Gynecology and Reproductive Biology, 153, 743-746. http://dx.doi.org/10.1016/j.ejogrb.2010.06.021

[10] Kiran, U., Hemmadi, S., Bethel, J. and Evans, J. (2005) Outcome of Pregnancy in a Woman with an Increased Body Mass Index. British Journal of Obstetrics and Gynaecology, 112, 768-772. http://dx.doi.org/10.1111/j.1471-0528.2004.00546.x

[11] Athukorala, C., Rumbold, A.R., Willson, K.J. and Crowther, C.A. (2010) The Risk of Adverse Pregnancy Outcomes in Women Who Are Overweight or Obese. BMC Pregnancy Childbirth, 10, 56-58. http://dx.doi.org/10.1186/1471-2393-10-56

[12] Weiss, J.L., Malone, F.D., Emig, D., Ball, R.H., Nyberg, D.A., Comstock, C.H., et al. (2004) Obesity, Obstetric Complications and Caesarean Delivery Rate-A Population-Based Screening Study. American Journal of Obstetrics \& Gynecology, 190, 1091-1097. http://dx.doi.org/10.1016/j.ajog.2003.09.058

[13] Poobalan, A.S., Aucott, L.S., Gurung, T., Smith, W.C.S. and Bhattacharya, S. (2009) Obesity as an Independent Risk Factor for Elective and Emergency Caesarean Delivery in Nulliparous Women-Systematic Review and Meta-Analysis of Cohort Studies. Obesity Reviews, 10, 28-35. http://dx.doi.org/10.1111/j.1467-789X.2008.00537.x

[14] Confidential Enquiry into Maternal and Child Health (2007) Saving Mother's Lives 2003-2005. RCOG, London.

[15] National Institute for Health and Clinical Exellence (2008) Antenatal Care: Routine Care for the Healthy Pregnant Woman. RCOG, London.

[16] Management of Women with Obesity in Pregnancy (2010) CMACE/RCOG Joint Guideline. RCOG Press, London.

[17] Metzger, B.E., Lane, L.P., Dyer, A.R., Trimble, E.R., et al. (2008) The HAPO Study Cooperative Research Group. Hyperglycemia and Adverse Pregnancy Outcomes. New England Journal of Medicine, 358, 1991-2002. http://dx.doi.org/10.1056/NEJMoa0707943

[18] Ratner, R.E., Christophi, C.A., Metzger, B.E., Dabelea, D., Bennett, P.H., Pi-Sunyer, X., Fowler, S., Kahn, S.E. and the Diabetes Prevention Program Research Group (2008) Prevention of Diabetes in Women with a History of Gestational Diabetes: Effects of Metformin and Lifestyle Interventions. Journal of Clinical Endocrinology \& Metabolism, 93, 4774-4779. http://dx.doi.org/10.1210/jc.2008-0772 